\title{
Learning And Leadership In The New Zealand Biotechnology Industry: Innovation And Human Capital In The New Economy
}

David Tweed

[Corresponding Author]

Judy McGregor
Department of Management

Massey University

Palmerston North

New Zealand

$\mathrm{Ph}(64) 63505799$

Human Rights Commission

Wellington

New Zealand

$\mathrm{Ph}$ (64) 44739981

Fax (64) 44716759

\begin{abstract}
Human capital for the "knowledge economy" has curiously been a Cinderella topic for applied business research. This paper reports on a survey of New Zealand small and medium enterprises and is part of a wider Government-funded new economy sector analysis. The study, which utilised both a quantitative survey and qualitative theory development, examines the motivation for innovation, perceived skill shortages and managerial priorities for future development. This paper utilises the biotechnology industry to explore the competencies required for increased profitability and growth. It examines the paradox that while the new economy is people reliant and the multi-disciplinary nature of modern management includes knowledge management as a principal managerial competency, these aspects have received too little research attention. It was prompted by industry and academic acknowledgment that the primary inhibitors to progress are not technological but managerial. The findings point towards a new model of technological learning.
\end{abstract}

\section{Introduction}

Robust rhetoric about New Zealand's knowledge economy is not necessarily matched by empirical findings. Gaps in research are being identified and addressed by university and industry researchers and examined by policy and business experts to ensure that New Zealand's knowledge and understanding of new wealth creating enterprises is contemporary and relevant. This paper reports on the results of an empirical investigation into the biotechnology industry.

\section{Literature}

It is fashionable to talk about the "new" economy and the "old" economy as if one was better than the other and more profitable. Recently it has been argued that such conclusions are spurious and the factors that influence business health are common to both. Michael Porter (2001), in analysing the internet economy, says that in periods of business flux it often appears as if there are new rules of competition. But, he says, 
"The creation of true economic value once again becomes the final arbiter of business success. Economic value for a company is nothing more than the gap between price and cost, and is reliably measured only by sustained profitability" (p.65).

We point this out not to be pessimistic about new expressions of innovation and entrepreneurship but to acknowledge that the companies we looked at face many of the same challenges of learning that confront all organisations. We also know, too, that the romance of the rhetoric - "new economy", "knowledge economy", and "knowledge wave" - disguises the reality of the struggle for innovative success.

Current New Zealand research into the new economy built on a prior three-year study that looked at removing impediments to technological uptake within small and medium size manufacturing enterprises in New Zealand (McGregor and Tweed, 2001). Two major insights were distilled from the previous project.

1. SME managers exhibited good technological understanding and did not perceive their needs to be in gaining greater technical understanding in relation to process or product development (McGregor et al, 2000). Instead, they indicated that they needed basic managerial competence improvements and nominated their needs in the "soft skill" areas of communication, strategic thinking and leadership. This insight about New Zealand business matches recent thinking in Europe. Cannell and Dankbaar (1996) note that within small and medium enterprises in Europe (about $80 \%$ of European companies) access to technological knowledge and knowledge transfer was less of a problem than access to organisational and marketing knowledge.

2. From the models and frameworks developed in relation to technology uptake (Kolb et al, 1999) we learnt that the more successful SMEs exhibited a number of competencies and capabilities working together. Therefore a company that was technologically advanced but with no marketing strategy and poor organisational systems was less likely to be doing well than an SME where all the competencies and capabilities were demonstrated. This showed us that technology alone was not the answer.

In a follow-up study conducted in 2001 we chose six small and medium new wealth-creating enterprises (McGregor, Tweed and Kolb, 2001) and conducted 25 interviews in Auckland, Wellington, Christchurch and Sydney with owner/managers, middle managers and professional workers, to provide more than one perspective on each company. The principal objective was to identify and study the way they undertook technological learning. We also wanted to further our understanding of managerial competence which Cobbenhagen (2000) suggests is "the glue which keeps it all together and the catalyst for achieving competitive advantage" and which we previously noted (Tweed and McGregor, 2000) as the knowledge, traits and skills required for a particular job or role. Table 1 provides a summary of the typical components that make up the competences required by new wealth creating enterprises. 
Table 1 - Breakthrough Dimensions for New Wealth Creating Enterprises

\begin{tabular}{|c|c|}
\hline $\begin{array}{l}\text { Breakthrough } \\
\text { Dimension }\end{array}$ & Typical components \\
\hline Technological & $\begin{array}{l}\text { Process innovation } \\
\text { Product innovation } \\
\text { Technology uptake } \\
\text { Technology transfer } \\
\text { Problem identification and problem solving } \\
\text { Learning and information management }\end{array}$ \\
\hline Marketing & $\begin{array}{l}\text { Profile development and reputation } \\
\text { Story development } \\
\text { Relationship building and client intimacy } \\
\text { Self belief and confidence in market offering(s) } \\
\text { Market positioning, penetration and development } \\
\text { Distribution systems } \\
\text { After sales customer care and service }\end{array}$ \\
\hline Organisational & $\begin{array}{l}\text { Systems development } \\
\text { Operations and processes } \\
\text { Supplier collaboration } \\
\text { Human capital development } \\
\text { Company culture and style }\end{array}$ \\
\hline Business & $\begin{array}{l}\text { Financial systems and management } \\
\text { Capital acquisition } \\
\text { Profitability } \\
\text { Enterprise establishment } \\
\text { Growth, expansion and diversification }\end{array}$ \\
\hline Managerial & $\begin{array}{l}\text { Leadership } \\
\text { Management style } \\
\text { Knowledge and traits } \\
\text { Competence and skill } \\
\text { Motivation, optimism } \\
\text { Networking, mentoring }\end{array}$ \\
\hline
\end{tabular}

In this paper we concentrate on marketing, managerial and organisational competences and their impact on technological learning. Much has been written about technological competence within the New Zealand context (Kolb et al, 1999). Managerial competence has received recent attention in New Zealand scholarship (McGregor and Tweed, 2001; Tweed et al, 2003).

New economy companies face many of the same challenges of learning that all organisations face. These include data capture, information management, idea dissemination and, ultimately, the problem of transforming individual knowledge into collective understanding. Both new and old economy companies need to have various kinds of knowledge, including 'know how', 'know why', 'knowing yourself' and 'knowing who' (Simpson et al, 2000) in order to be successful. But, in many cases, that is where the similarities end.

Perhaps it is not so much the differences in the companies themselves, but the differences in their learning environment which are noteworthy. Accelerated time-to-market cycles, increasing interest and intervention of governments, regulation and protection, fierce and, often invisible, global competitors make it difficult to remain optimistic and 'loose' enough to learn. Indeed, knowing 'how' and knowing 'why' can be strongly stimulated by necessity and/or threats to survival. These states, however, can also be counterproductive to other forms of learning, including knowing oneself and knowing (and trusting) others. 
Strong values of individualism underpinning the new economy can fundamentally undermine collective knowledge, sharing and learning. Problems exist when information and wisdom is stored within a few key individuals' heads, making the firm more reliant on those individuals, or vulnerable to their departure.

New economy companies see learning as imperative - a do or die situation and, at the same time, just the normal way of doing business. While the imperative to learn is clear, new economy companies also learn how to filter the masses of information available and become skilled at how to learn on demand, finding what they need to know, when they need to know it. In this sense, a latent capability to access information can be more effective than attempting to 'know it all'.

The learning path of new economy companies can best be described as two coinciding and interdependent pathways. One developmental path takes place as the firm discovers how to do things - what works and what doesn't work. This type of learning accompanies product development and includes experience (trial-and-error), cognition (analysis, reflection) and integration (new working hypotheses and/or ideas). The underlying theory here is one of experiential learning.

The second path of development is part of the process enhancement aspect of the firm. It is determined by, and determines in the future, issues surrounding who we are, why we are doing this and how are we doing in relation to others. The underlying theories here are social learning (Kreitner \& Luthans, 1984) and social identity (Mael and Ashforth, 1992).

\section{Biotechnology industry study}

In order to further our understanding of managerial competence and technological learning a survey questionnaire was sent to all New Zealand companies located primarily in biotechnology (149) and of these 65 companies completed and returned the questionnaire resulting in a response rate of $43.6 \%$. The survey was completed by chief executives, general managers, company directors or other senior management.

\section{Characteristics of NZ Biotechnology Enterprises}

Over a third of the biotechnology companies who responded to the survey (39.1\%) produced and/or sold biotechnology products, $26.1 \%$ said they researched into biotechnology. A small number $6.7 \%$ supported biotechnology organisations through the provision of finance, legal and government services and $28.2 \%$ said "other" which included a wide variety of related businesses from education about biotechnology through to consulting and marketing.

Respondents were asked which area best described their market(s) from a list of ten identified areas supplied by industry to the researchers with an unstructured "other" option. About a third (33.2\%) were in New Zealand's traditional agricultural area - meat (14\%), dairy (11.8\%) and other agriculture (7.4\%). The highest single category was natural products (including health foods) at $20.8 \%$. Other markets identified were biotechnology (10\%) nutraceuticals/dietary supplements $(8.9 \%)$ and a smaller number identified diagnostics, forestry, horticulture and pharmaceuticals as their main markets

The majority of the respondents were small or medium sized enterprises. A total of $26 \%$ had ten or less employees and a further $21 \%$ had between eleven and fifty employees. Three of the companies in the sample had over 500 employees. The tenure of the sample companies was interesting in that one company had been in existence for over 100 years while others were recent start-ups only a year old. Most of the respondent companies had been in existence for around 15 years.

The survey asked participant companies several questions about their performance which related primarily to operations within New Zealand. Almost half of the respondent companies (48.4\%) had between $\$ 1$ and $\$ 10$ million dollars income from sale of products or services in the previous financial year, with $25 \%$ of sample companies having sales up to $\$ 1$ million and $26.6 \%$ of sample companies having sales over $\$ 10$ million. Two companies said they had sales of more than $\$ 100$ million. 


\section{Research and development expenditure}

The majority of the companies (58.5\%) indicated that over the past two years total research and development expenditure had been increasing, with 35.8\% saying it had held its own and 5.7\% indicating a decrease. The expenditure on research and development for the last financial year was clustered below the $\$ 500,000$ range with $17.5 \%$ of companies stating they had spent nothing, $25.4 \%$ spent up to $\$ 99,000$ and $23.8 \%$ spent between $\$ 100,000$ and $\$ 499,000$. A further $15.9 \%$ of companies invested between $\$ 500,000$ and $\$ 1.9$ million. About ten per cent of companies spent more than $\$ 2$ million on research and development in the last financial year.

\section{Future plans}

Well over three quarters of the respondents, 79.7\%, could be described as expansionist in intentions with $34.4 \%$ indicating that they were seeking to grow significantly over the next 12 months and $45.3 \%$ seeking to grow moderately. A total of $17.2 \%$ were seeking to stay the same size and a tiny number wanted to become smaller.

The vast majority, $81.5 \%$, indicated they were actively exploring new markets. About a third of the sample indicated that the development of new products and technologies was not relevant. Two thirds of respondents did develop new products and they indicated it took an average 3.6 years to get the products of research and development into the marketplace with the range being from six months to 15 years.

About a third of the sample was exporting to Australia, United States, United Kingdom and Europe, South East Asia and Japan as dominant markets. The majority of respondents, $87.7 \%$ said they had a clearly defined business concept or model for their businesses while a lesser number, $66.2 \%$, said they had a current written business plan.

\section{New Products}

Over a third of companies had not developed any completely new products or technologies in the past two years. Of the sample companies who had developed new products, the average number of new products or technologies was five and $11.9 \%$ of their current income had resulted from them. About half of these companies intended to manufacture these products and for more than two thirds of respondents the returns or value gained from these products relied on intellectual property protection.

\section{Innovation}

The need to innovate (Cobbenhagen, 2000) appears to be universal, irrespective of size, sector or technological sophistication and innovation is often seen as the driver of progress in industry. Respondents were asked to comment on the motivation to pursue innovation (see Table 2). The top motivations resulting in innovation are all market-related with increasing market share being the most prominent $(86.0 \%)$ followed by the desire to open up new markets $(79.7 \%)$ and extend the product range (78.9\%). It is interesting that operations-based motivations lag far behind with improving productivity (48.3\%) nonetheless ahead of cost reduction (39.7\%). 
Table 2 - Motivation to pursue innovation

\begin{tabular}{|l|l|}
\hline & $\%$ \\
\hline Maintain or increase our market share & 86.0 \\
Open up new markets & 79.7 \\
Extend the range of our products & 78.9 \\
Improve the quality of our products & 71.9 \\
Improve productivity & 48.3 \\
Reduce costs & 39.7 \\
\hline Note: The percentage reports those who agreed or strongly agreed \\
\hline \multicolumn{2}{|c|}{ that the item was a reason that innovation was pursued } \\
\hline
\end{tabular}

Triggers for innovation most identified by sample companies reinforce market and competitive imperatives (Table 3). Customer need, an externally focused trigger, combined with profitability and internally-focused creativity through new ideas were identified as the top innovation triggers, closely supported by the need for continuous improvement.

Table 3 - Innovation triggers

\begin{tabular}{|l|l|}
\hline & $\%$ \\
\hline Customer need & 66.1 \\
The need for more profit & 66.1 \\
A new idea generated internally & 66.1 \\
Need for continuous improvement & 60.3 \\
Strategic planning & 57.9 \\
Identification of a technology gap & 53.4 \\
Availability of new technology & 44.1 \\
Staff suggestions/ideas & 42.1 \\
Competitions & 37.9 \\
Management directive & 36.8 \\
Suppliers & 17.2 \\
Changing regulations or law & 12.1 \\
\hline Note: The percentage indicates those who felt that the item 'often' or \\
\hline \multicolumn{2}{|c|}{ 'always' acted as a trigger for innovations } \\
\hline
\end{tabular}

Traditionally, suppliers have been viewed as a strong source of innovative ideas, but this factor ranks low in biotechnology companies with just $17.2 \%$ indicating that suppliers are an innovation trigger. While suppliers may be less important as the trigger for innovation they are often able to provide assistance and ideas for meeting an innovation challenge. Thus, their role is one of providing solutions once the need for innovation is recognised.

\section{Human Capital}

\section{Skill shortages}

Interestingly, technological skills and a combination of technical and business were identified by sample companies as enterprise level labour shortage issues (Table 4). 
Table 4 - Enterprise level skill shortages

\begin{tabular}{|l|l|}
\hline Skill area & $\mathbf{\%}$ \\
\hline Technical/Science & 53.3 \\
\hline Combination of technical/science and business & 51.7 \\
\hline Marketing & 33.8 \\
\hline Staff/employees [non-management] & 25.0 \\
\hline University graduates & 23.3 \\
\hline Management level staff & 21.7 \\
\hline Financial & 11.7 \\
\hline Note: Respondents each answered with respect to their organisation. The \\
\hline
\end{tabular}

This again reflects the strong research-based culture of many biotechnology enterprises and the need to combine strong technical expertise with commercial acumen. This need for "business smarts" is emphasised again at industry level (Table 5) by the focus on marketing which is seen industry wide as the second most important skill deficiency $(76.5 \%)$

Table 5 - Perceptions of Industry level skill shortages

\begin{tabular}{|l|l|}
\hline Skill area & \% \\
\hline Combination of technical/science and business & 82.4 \\
\hline Marketing & 76.5 \\
\hline Management level staff & 52.9 \\
\hline Technical/Science & 50.0 \\
\hline Financial & 47.1 \\
\hline University graduates & 45.7 \\
\hline Staff/employees [non-management] & 23.5 \\
\hline Note: Respondents each answered with respect to their organisation. The \\
\hline \multicolumn{2}{|l}{ percentage is given for those that answered 'yes' } \\
\hline
\end{tabular}

Government, policy makers and industry are all aware of New Zealand's current shortage of technological expertise to drive the knowledge economy. We address the educational ramifications in the conclusions section of this paper.

\section{Current ability levels}

Increasingly business researchers and industry are acknowledging that the primary bottleneck to progress is not so much technology but management. Our respondents rated the ability of their management team in 52 areas of competence and the top ten are reported in Table 6 . The priority attached to new ideas in the biotechnology industry is clearly identified by respondents who ranked it the top area by current ability. Three marketing competencies recognising opportunity, identifying customer needs, and building customer loyalty were also seen by respondents as things they consider they currently do well. Equally they feel they are strongly computer literate 
Table 6 - Top ten areas by current ability

\begin{tabular}{|l|l|l|l|}
\hline Competence area & $\begin{array}{l}\text { Low or } \\
\text { very low } \\
\%\end{array}$ & $\begin{array}{l}\text { Med } \\
\%\end{array}$ & $\begin{array}{l}\text { High or } \\
\text { very high } \\
\%\end{array}$ \\
\hline Generating ideas & 1.6 & 21.0 & 77.4 \\
\hline Recognising opportunity & 1.6 & 31.1 & 67.2 \\
\hline Using computers and software & 7.9 & 27.0 & 65.1 \\
\hline Identifying customer needs & 6.7 & 28.3 & 65.0 \\
\hline Building customer loyalty & 15.3 & 20.3 & 64.4 \\
\hline Monitoring cashflow & 4.8 & 31.7 & 63.5 \\
\hline Maintaining open communication & 1.6 & 36.5 & 61.9 \\
\hline Problem solving & 3.3 & 36.1 & 60.7 \\
\hline Self management and motivation & 6.6 & 32.8 & 60.7 \\
\hline Managing costs & 6.3 & 33.3 & 60.3 \\
\hline
\end{tabular}

\section{Priorities for further development}

The current strengths of managers do not always reflect their priorities for development (Table 7). Interpersonal skills were identified as significant competencies needing further work by biotechnology companies, with listening ranked highest as a priority for future development and maintaining open communication ranked fourth,.

Table 7 - Top ten priorities for development

\begin{tabular}{|l|l|l|l|}
\hline Competence area & $\begin{array}{l}\text { Low or } \\
\text { very low } \\
\%\end{array}$ & $\begin{array}{l}\text { Med } \\
\%\end{array}$ & $\begin{array}{l}\text { High } \\
\text { very } \\
\%\end{array}$ \\
\hline Listening & 3.4 & 15.3 & 81.4 \\
\hline Identifying customer needs & 0.0 & 20.7 & 79.3 \\
\hline Building customer loyalty & 1.7 & 19.0 & 79.3 \\
\hline Maintaining open communication & 3.4 & 18.6 & 78.0 \\
\hline Setting goals and objectives & 1.8 & 21.1 & 77.2 \\
\hline Recognising opportunity & 1.8 & 21.1 & 77.2 \\
\hline Selling products, services, technologies & 3.5 & 19.3 & 77.2 \\
\hline Motivating others & 5.2 & 19.0 & 75.9 \\
\hline Recognising the skills of others & 1.8 & 22.8 & 75.4 \\
\hline Strategic and business planning & 3.5 & 21.1 & 75.4 \\
\hline
\end{tabular}

The emphasis on active listening is linked to the marketing competencies 'identifying customer needs' and 'building customer loyalty' which were also highly ranked. It can be concluded that New Zealand biotechnology companies could better foster an internal locus of control through development of motivational skills and team development through acknowledging the skills of others.

The research design allowed for a contrast of the gaps between perceptions by respondents of current ability and their priorities for future development (Table 8). A strong leadership orientation immediately emerges as the key area where there is the largest opportunity for managerial capacity building in the industry. 
Table 8 - Top Ten Competence Gaps

\begin{tabular}{|l|l|l|}
\hline Competence area & Classification & Gap $^{\mathbf{1}}$ \\
\hline Delegating effectively & Leadership & 31 \\
\hline Linking rewards to performance & Leadership & 22 \\
\hline Improving performance & Leadership & 22 \\
\hline Selling products, services and technologies & Marketing & 21 \\
\hline Setting goals and objectives & Planning and Operations & 21 \\
\hline Training and developing staff & Leadership & 19 \\
\hline Motivating others & Leadership & 19 \\
\hline Obtaining feedback & Interpersonal & 16 \\
\hline Listening & Interpersonal & 14 \\
\hline Strategic and business planning & Planning and Operations & 12 \\
\hline $\begin{array}{l}\text { 1. The 'gap' is the difference between the current ability ranking and priority for development } \\
\text { ranking of the 52 competencies. This scale has a mid-point of zero and a potential spread of } \\
-51 \text { to +51. All of the items above are strongly positive. }\end{array}$ \\
\hline
\end{tabular}

The emphasis on leadership suggests that building organisational competence requires increased leadership capacity that provides the environment and positive tension for contemporary human capital development.

\section{Discussion}

What does the survey of biotechnology companies contribute to the model of technological learning in New Zealand's knowledge economy? It shows that leadership and marketing factors are the outstanding areas of perceived need identified by biotechnology companies themselves. Industry members acknowledge that high priorities for self-development include listening, building loyalty, identifying customer needs and maintaining open communication. Human factors are seen by sample companies as being levers for growth and development. External and internal leadership emerges as a dominant theme in the biotechnology results.

If marketing is a preeminent competence underpinning technological learning in the new economy it may presuppose a reversal of the paradigm of production to marketing. The new economy business orientation suggests that marketing innovation is as important as technological innovation in growth strategies. The classic distinction between technology-push and market-pull is too simplistic. Instead the notion of marketing foresight builds on technological capacity and means business can lead the market as well as follow it.

We know from previous work that human capital, and managerial competence in particular, has been the Cinderella topic in the ebb and flow of debate about the knowledge economy. From successive studies located within SMEs in New Zealand it is now possible to be much more specific about the managerial competence elements that need attention. They relate to skills, knowledge and personal attributes associated with recognizing opportunity, identifying new markets, and the development of a company "story" for internal validation and external profile.

Additionally it is not only development of customer loyalty and customer service but the anticipation of those needs that is the new required mindset. Cobbenhagen (2000) notes that front-runners adopt an assertive attitude towards their customers. Listening was the highest priority for competence development in the biotechnology industry, but listening alone, while important, may not be enough. Front-runners also have to convince customers that the product or service is what they need. Internal leadership plays a significant part in this process - leadership that is dynamic, flexible and modern.

Other barriers to growth identified by respondents, such as issues relating to legal and regulatory compliance both within New Zealand and overseas, probably also reflect the absence of strong industry wide lobbying that might reduce or spread compliance costs and improve legal and regulatory understanding. The will to grow is evident, nevertheless, with a high number of companies (34.9\%) seeking to grow significantly in the next twelve months and a further $45.3 \%$ wanting to grow moderately. 
At a policy level the infrastructural support provided to biotechnology needs to address identified skill shortages in the technical and business areas. Marketing skills again were ranked highly as in short supply. Biotechnology businesses know they need to be more creative and develop strategies and toolkits that push growth and sustainability through marketing competence. The three legs of technology, business and marketing need to be at the epicentre of a radical overhaul of undergraduate business education for it to be more relevant to the new economy. Many business educators work in disciplinary silos and curriculum is often dictated by academic turf wars rather than a commitment to changing business realities. Much closer partnerships are needed between industry sectors such as biotechnology and tertiary providers. Perhaps greater industry involvement in curriculum design, delivery and moderation is necessary to increase the relevance and business-preparedness of graduates and could be achieved without prejudicing academic autonomy.

\section{New model of technological learning}

An effective model of technological learning in the New Zealand context which is bound largely by the aspirations of SMEs, therefore, has as its centre marketing foresight (see Figure 1). A first iteration of this model was developed from our previous work with software companies (Tweed and McGregor, 2003). This model was further developed as a result of the insights gained from biotechnology companies. While previous aspects of the model are confirmed, the new data promoted leadership to the top of the managerial competence hierarchy. While the first iteration of the model acknowledged human capital, it did not particularise the communication skills so clearly identified by the biotechnology respondents. A further element added to the model of technological learning involved work around the macro-environment to include the importance of legal and regulatory compliance in a globalised economy.

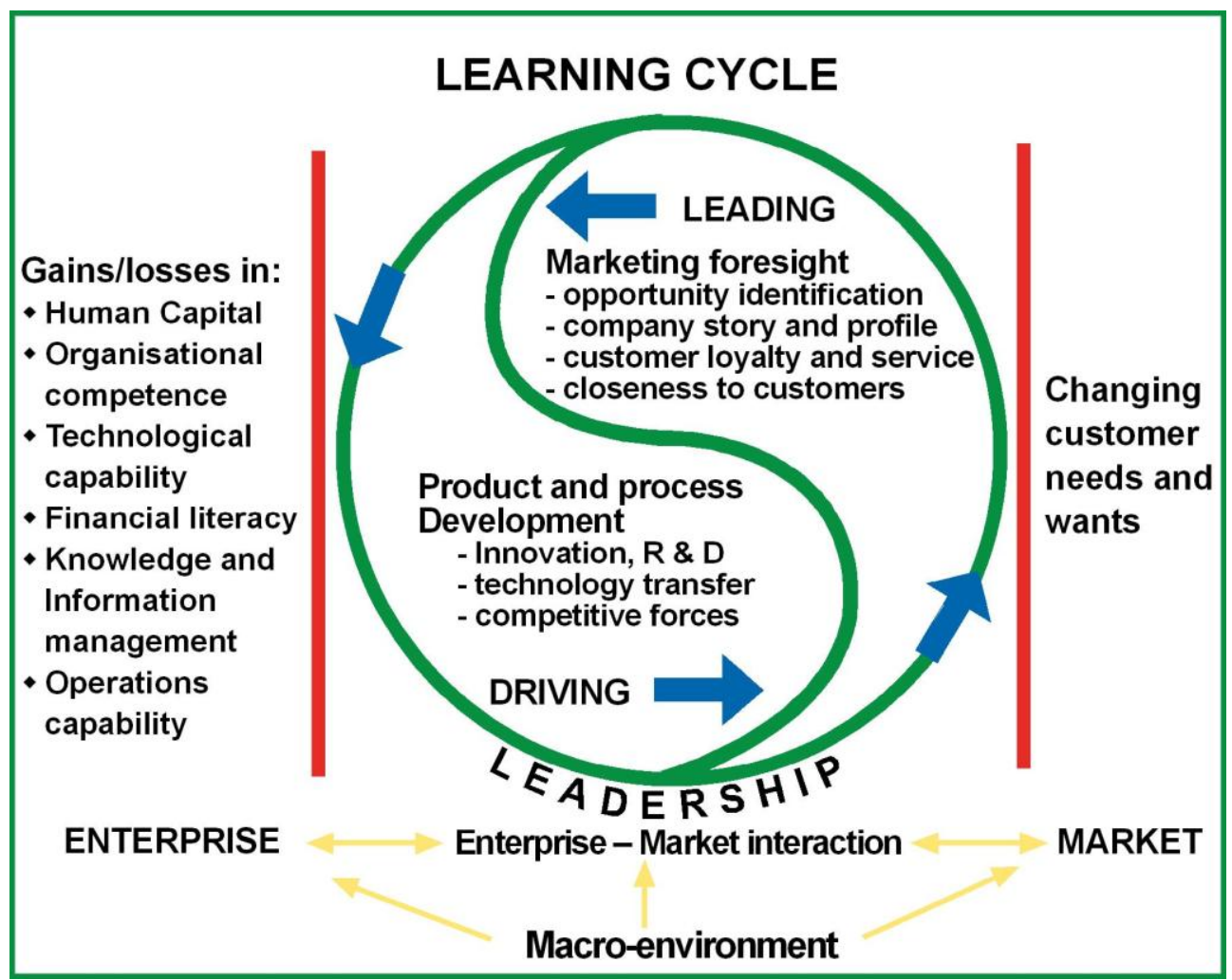

Figure 1 - Model of Technological Learning for New Economy Enterprises

The new model of technological learning is the engine of innovative effort within the firm but sits within the larger context of resources and enterprise outcomes. The connection between resources, learning and profitability is shown in Figure 2. 


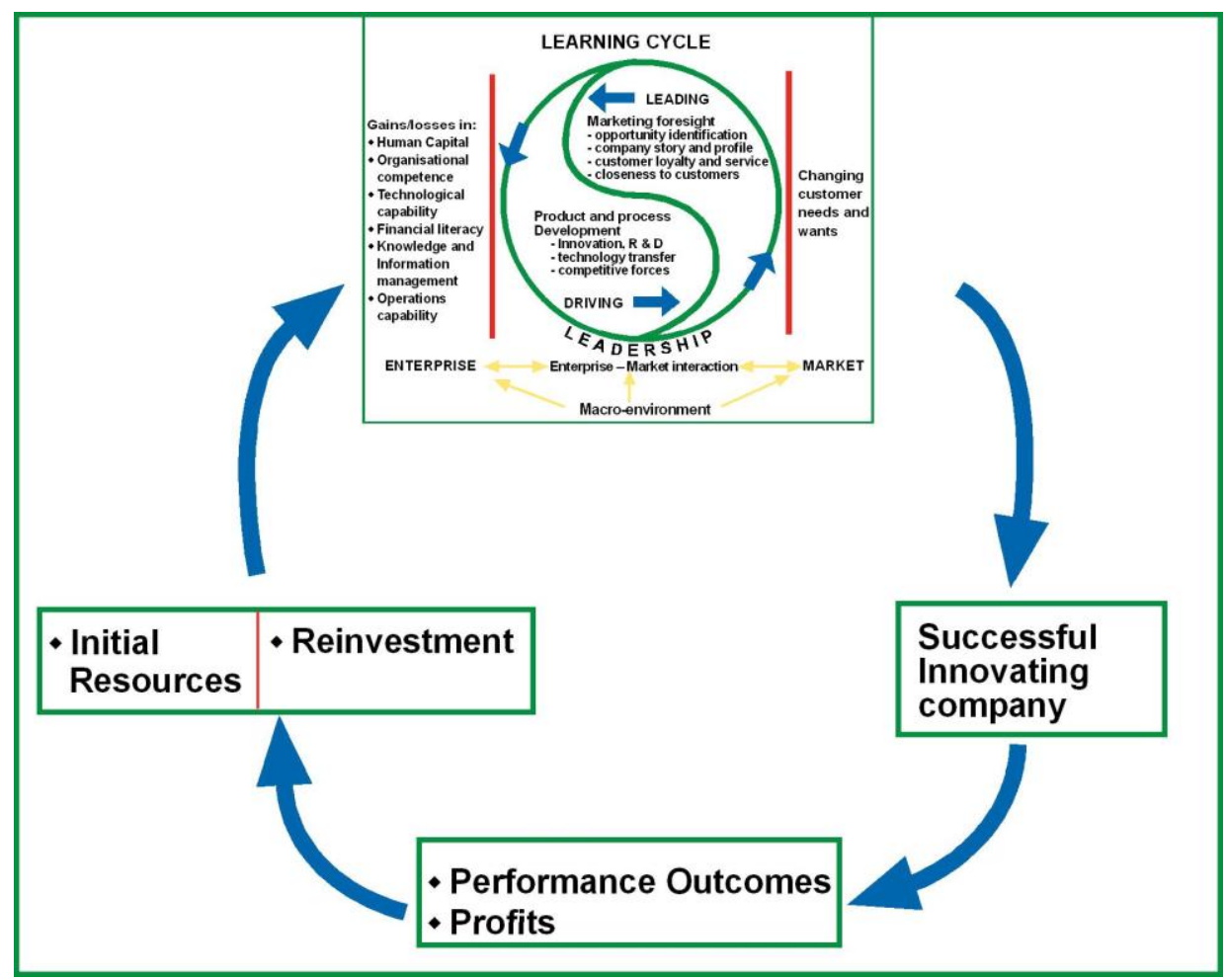

Figure 2 - The context and outcomes of technological learning

The model of technological learning is therefore the driver or engine of a cycle of business renewal, change and growth.

In conclusion it is necessary to keep Porter's (2001) caveat in mind, that in times of business flux it appears as if new rules of competition are in play, whereas he reminds us that the final arbiter of business success is sustained profitability. The need to develop marketing foresight and to rethink managerial learning is key to sustained profitability and it appears that those companies that build their technological learning on market orientation will enjoy competitive advantage in the new economy.

\section{References}

1. Cannell, W. and Dankbaar, B. (1996) Technology Management and Public Policy in the European Union. Oxford: Oxford University Press

2. Cobbenhagen, J. (2000) Successful Innovation. Cheltenham, UK: Edward Elgar.

3. Kolb, D. (Ed), Tweed, D.M., Simpson, B., Seidel, R., McGregor, J.H., and Henley-King, J. (1999) Technology Uptake in New Zealand Manufacturing. Palmerston North: Massey University.

4. Kreitner, R. and Luthans, F. (1984). A social learning approach to behavioural management. Organisational Dynamics, autumn.

5. Mael, F. and Ashforth, B. E. (1992). Alumni and their alma mater: A partial test of the reformulated model of organisational identification. Journal of Organisational Behaviour, (13) 103-123.

6. McGregor, J.H., Kolb, D., Tweed, D.M., Henley-King, J., Simpson, B., and Seidel, R. (2000) Managing for success: a training kit about innovation for New Zealand manufacturers. Massey University: Palmerston North.

7. McGregor, J.H. and Tweed, D.M. (2001). Facing the challenge of improving managerial competence in small business: The New Zealand experience. 2001 An Enterprise Odyssey: 31st European Small Business Seminar [CD-ROM], September 12-14, Dublin, Ireland. Brussels: European Foundation for Management Development. 
8. McGregor, J.H., Tweed, D.M. and Kolb, D. (2001) Exploring New Economies Companies in New Zealand. NZ: Massey University

9. McGregor, J.H. and Tweed, D. (2001). Gender and managerial competence: support for theories of androgyny? Women in Management, 16 (5/6), 279-286.

10. Porter, M.E. (2001) Strategy and the internet. Harvard Business Review, March. pp 63-78.

11. Tweed, D.M. and McGregor, J. (2003) Moving Forward in the New Economy: Lessons from Software Companies. Palmerston North; Massey University

12. Tweed, D.M. and McGregor, J.H. (2000) Linking competence with goal attainment in SMEs: An examination by management tenure, size, structure, innovation and growth. In R. Sanchez and A. Heene. Research in Competence-Based Management. Part C. Stamford, Connecticut: JAI Press Inc.

13. Tweed, D.M., McGregor, J.H., Pech, R. and Wallace, C. (2003) Making Capital in the New Economy: The Role of Management Competence. Proceedings of the Hawaii International Business Conference held $18^{\text {th }}$ to $21^{\text {st }}$ June 2003 pp $1-10$ 